* Doutorando em Direito Civil pela Universidade Federal de Minas Gerais. Mestre em Direito Civil pela Universidade de Coimbra - Portugal. Professor de Direito Civil na Faculdade IBMEC-MG e na Faculdade de Direito Milton Campos. E-mail: fabio.queiroz (a)gmail.com

\section{O Direito Comercial e a formação histórica do princípio da boa-fé objetiva}

\section{The Commercial LAW AND THe historical FORMATION OF THE PRINCIPLE OF OBJECTIVE GOOD FAITH}

\author{
Fabio Queiroz Pereira *
}

Resumo: O presente trabalho aborda o desenvolvimento histórico do princípio da boa-fé objetiva, tendo por cerne as relações jurídicas de natureza comercial. O tema é explorado a partir dos atuais contornos da boa-fé objetiva. A partir da aludida base conceitual, são traçados alguns cortes históricos, buscando demonstrar a influência do direito comercial no surgimento e desenvolvimento da boa-fé objetiva, notadamente, em decorrência do cosmopolitismo que caracteriza esse ramo jurídico. Verificou-se, assim, que os usos e costumes comerciais, os juramentos de honra e a jurisprudência comercial alemã são pontos de extrema importância para a atual compreensão de boa-fé objetiva.

Palavras-chave: Boa-fé objetiva. Direito comercial. História do direito comercial.

Abstract: This paper discusses the historical development of the objective good faith, based on the legal relationships of commercial character. The theme is explored from the current contours of objective good faith. From the mentioned conceptual basis, are plotted some historic cuts, seeking to demonstrate the influence of commercial law in the emergence and development of objective good faith, especially as a result of cosmopolitanism that characterizes this area of law. It is seen, therefore, that the trade usages, the oaths of honor and german commercial jurisprudence are points of extreme importance to the current understanding of objective good faith.

Keywords: Objective good faith. Commercial law. History of commercial law. 


\section{INTRODUÇÃO}

Contemporaneamente, a boa-fé objetiva é compreendida como princípio essencial a vincular todas as relações de direito obrigacional. Trata-se de referência imprescindível, que permeia a atuação de todos os agentes, nos mais variados ordenamentos jurídicos. Falar em boa-fé objetiva significa estar adstrito a valores de cunho ético desenvolvidos no seio de um grupo social ${ }^{1}$. Denota, ainda, inserir na ordem jurídica padrões de conduta concebidos como adequados e que devem ser seguidos, tratando-se de verdadeiras expressões de justiça ${ }^{2}$.

O conceito de boa-fé alcançou espaço demasiadamente significativo na cultura jurídica universal, apesar de estar inserido no pensamento científico desde tempos mais remotos ${ }^{3}$. As ilações envolvendo a temática são resultados de debates travados nos mais variados campos do Direito que, por sua vez, têm como objetivo constante a delimitação do conteúdo e alcance da aplicação desse novo matiz principiológico ${ }^{4}$.

Apesar de sua destacada importância no âmbito das relações de natureza cível, a boa-fé objetiva possui grande aplicação no campo do direito comercial. Os contratos travados pelas empresas devem ser necessariamente ponderados e interpretados tendo por cerne axiológico a boa-fé objetiva. Os deveres laterais, como a lealdade, a probidade, ou mesmo os deveres de informação, vinculam as relações obrigacionais travadas no âmbito empresarial. Ademais, os vínculos relacionais existentes dentro da sociedade empresarial - figura elementar para

\footnotetext{
${ }^{1}$ Em mesma perspectiva, afirma Carlos Alberto da Mota Pinto (2005, p. 124): “A boa fé é hoje princípio fundamental, particularmente relevante no campo das relações civis e, mesmo, de todo o direito privado. Exprime a preocupação da ordem jurídica pelos valores extra-jurídicos da comunidade, pelas particularidades da situação concreta a regular e por uma juridicidade social e materialmente fundada".

2 Nesse sentido, Massimo Bianca (2000, p. 423) aduz: "La buona fede non ha un contenuto prestabilito ma è un pricipio di solidarietà contrattuale che si specifica in due fondamentali aspetti, quello della salvaguardia (attivarsi per salvaguardare l'utilità dell'altra parte nei limiti di un apprezzabile sacrificio) e della lealtà".

${ }^{3}$ Sobre a constatação da boa fé em tempos remotos, assevera Menezes Cordeiro (2007, p. 18): "Os jurisprudentes romanos intentaram descobrir, num mar de decisões empíricas, encontradas na busca de um equilíbrio, capaz de suscitar consenso, manifestações de regularidade que, permitindo tratar o igual, por igual, e o diferente, de modo diferente, de acordo com a medida da variação, tornassem previsíveis as saídas para litígios futuros. Fazendo-o, fundaram a Ciência do Direito onde, de imediato, se incluiu a boa fé".

${ }^{4}$ É importante estar atento, contudo, aos discursos falaciosos e vazios envolvendo a boa fé. Nesse sentido, Menezes Cordeiro (2007, p. 41) adverte: "A boa fé sofre, na actualidade, as consequências do divórcio entre os discursos metodológicos oficiais e a dogmática jurídica. E de modo agravado: noção vaga, carregada de história, rica em implicações emotivas e objecto de utilização alargada, embora de contornos pouco conhecidos, ela presta-se, por excelência, a desenvolvimentos verbais, numa aporética dominada por uma linguagem grandiloquente e vazia de conteúdo. Há uma mitificação da boa fé”.
} 
o direito comercial -, por estarem adstritos à confiança recíproca, exprimem, de forma ainda mais candente, a necessária persecução da boa-fé objetiva em suas questões.

Nesse contexto, revela-se necessário o estudo do desenvolvimento da boa-fé objetiva, tendo por cerne as relações jurídicas de natureza comercial. Tal exercício revela-se ainda mais elementar quando as fontes históricas e as indagações acerca das origens do aludido princípio parecem demonstrar a importância fulcral do direito comercial no seu surgimento e no seu desenvolvimento, notadamente, em decorrência do cosmopolitismo que caracteriza esse ramo jurídico.

\section{CONTORNOS DA BOA-FÉ OBJETIVA}

Para o adequado enquadramento da matéria, faz-se importante distinguir a boa-fé objetiva da boa-fé de ordem subjetiva. Diferenciá-las, mesmo que seja de maneira superficial, é exercício que deve ser feito para que não se recaia em inadvertências e desordens de conceituação.

Nesse ínterim, importa assinalar que a modalidade subjetiva da boa-fé cinge-se ao campo psíquico, aferindo-se a intenção e a vontade do agente. Tem-se em vista a situação de quem julga atuar em conformidade com o Direito, por desconhecer ou ignorar qualquer vício ou circunstância anterior (PINTO, 2005, p. 124). A pessoa que subjetivamente encontra-se em boa-fé age acreditando ser detentora de um direito que só existe aparentemente, alimentando uma expectativa que não encontra fulcro na ordem jurídica ${ }^{5}$.

No ordenamento jurídico brasileiro, é possível se deparar com exemplos de concretização da boa-fé subjetiva no art. 309, do Código Civil, quando este aduz que o pagamento feito de boa-fé ao credor putativo é válido, ainda provado depois que não era credor, ou no art. 1201, do mesmo diploma, em que se afirma que é de boa-fé a posse, se o possuidor ignora o vício ou o obstáculo que lhe impede a aquisição da coisa.

Esclarecidas as nuances elementares da boa-fé subjetiva, importa delimitar o conceito e o alcance da modalidade objetiva, tendo em vista que esta possui demasiada importância para os novos deslindes encontrados no atual direito

\footnotetext{
${ }^{5}$ Neste sentido: "Na situação de boa-fé subjetiva, uma pessoa acredita ser titular de um direito, que na realidade não tem, porque só existe na aparência. A situação de aparência gera um estado de confiança subjetiva, relativa à estabilidade da situação jurídica, que permite ao titular alimentar expectativas, que crê legítimas" (NORONHA, 1994, p. 132).
} 
obrigacional. A boa-fé objetiva possui relevo ímpar, pois se demonstra como supedâneo axiológico dos novos contornos jurídicos da figura do contrato e perpassa necessariamente por uma ponderação ética a ser concretizada em determinado meio social.

O aludido princípio materializa-se por meio da chamada cláusula geral. Isso significa que a boa-fé objetiva vigora sobre toda a ordem jurídica; os preceitos genéricos e abertos de uma determinada legislação deverão ser sempre compreendidos e aplicados em consonância com a boa-fé. Especificamente no campo contratual, observa-se que é necessária uma adequada interpretação do texto pactuado, restando um importante trabalho hermenêutico a ser exercitado pelos operadores do Direito, destacadamente, pela figura do juiz.

No âmbito do Direito Civil brasileiro, a boa-fé objetiva foi positivada a partir do texto do Código Civil de $2002^{6}$. A nova codificação procurou inovar, dando especial atenção à nova principiologia contratual. Dispõe o art. 422, do referido diploma civil, que os contratantes são obrigados a guardar, assim na conclusão do contrato, como em sua execução, os princípios de probidade e boa-fé. Em soma a essa norma, e de forma mais extensiva, observase o art. 113, que prevê que os negócios jurídicos devem ser interpretados conforme a boa-fé.

Interessante observar que o exercício de identificação e aplicação da boa-fé objetiva é variável em razão de uma gama de subsídios que, por sua vez, se encontram vinculados ao espaço físico e ao elemento temporal. Tratase de característica que, em última medida, perfilha a abstração contida no conceito. Isso quer dizer que o agir em consonância com a boa-fé deve estar inserido dentro de um contexto maior: dependendo da época e do local, os padrões de conduta esperados das partes contratantes, por exemplo, podem variar.

O principal campo de verificação da boa-fé dá-se, especialmente, na seara contratual, onde adquire o desenho de regras de conduta. A boa-fé objetiva está intrínseca a qualquer modo de contratação, exigindo um adequado comportamento das partes contratantes. A deslealdade, a desonestidade, o silêncio diante de informação relevante ou mesmo a ausência de colaboração

\footnotetext{
${ }^{6}$ O Código Civil brasileiro de 1916, elaborado tendo por pálio as ideias pandectistas do século XIX, não alude à boa fé em seu sentido objetivo. Segundo Antônio Junqueira de Azevedo (1992, p. 81), "há, nessa omissão do Código Civil Brasileiro, um reflexo da mentalidade capitalista da segunda metade do século XIX, mais preocupada com a segurança da circulação e desenvolvimento das relações jurídicas do que com a justiça material dos casos concretos".
} 
são atitudes que colocam em xeque o comportamento contratual que pretenda estar em consonância com o dito princípio. A exigência legal das referidas condutas é perfilhada pelos denominados deveres acessórios, que atuam dirigindo o procedimento dos particulares no momento da contratação ${ }^{7}$.

Desse modo, o contrato passa a conter cláusulas que não estão necessariamente expressas no instrumento pactuado, mas que derivam do imperativo de se agir de acordo com os padrões exigidos pela boa-fé. Nessa contenda, deveres de fornecer corretas informações e esclarecimentos, deveres de lealdade, deveres emanados da correção e da lisura, dentre uma grande gama de obrigações, devem ser seguidos e respeitados, resultando em adequado comportamento das partes contratantes.

Essas obrigações, preconizadas sob a forma de deveres laterais das partes contratantes, muitas vezes, assumem a forma do chamado princípio da confiança. A referida cláusula geral da boa-fé visa a tutelar as expectativas que cada uma das partes possui em razão da pactuação de um contrato. Um indivíduo, ao concluir um negócio jurídico, espera determinados comportamentos que devem ser desempenhados pela parte contrária. Nesse sentido, costumase dizer que a boa-fé concretiza-se na tutela da confiança ${ }^{8}$. Busca-se proteger a confiança que uma parte deposita no momento da contratação, em razão da conduta alheia, resguardando-se a crença no fato de que a contraparte respeitará determinados perfis de comportamento, que se esperam das pessoas probas.

Relativamente ao campo contratual, a doutrina costuma reconhecer à boa-fé objetiva algumas funções essenciais. A primeira é relativa ao processo interpretativo, devendo a boa-fé conduzir o operador do Direito no exercício

\footnotetext{
${ }_{7}^{7}$ Nesse ponto, acrescenta Carlos Alberto da Mota Pinto (2005, p.125): "É ainda a boa fé que em certa medida conforma a relação contratual, pois é ela um dos critérios a que se recorre para determinar o âmbito da vinculação negocial. Quer dizer que do contrato fazem parte não só as obrigações que expressa ou tacitamente decorrem do acordo das partes, mas também, designadamente, todos os deveres que se fundam no princípio da boa fé e se mostram necessários a integrar a lacuna contratual. Nesta linha, importa sublinhar o papel decisivo da boa fé no enriquecimento do conteúdo do contrato, mormente por constituir a matriz dos denominados deveres laterais, como os deveres de cuidado para com a pessoa e o patrimônio da contraparte, os deveres de informação e esclarecimento, etc.".

${ }^{8}$ Em mesmo sentido: "Várias das soluções legislativas que apelam ao princípio da boa fé em sentido objectivo são em grande medida inspiradas pela necessidade da tutela da confiança. Trata-se, no fundo, de acolher a ideia de que em certos casos, deve relevar juridicamente a confiança justificada de alguém no comportamento de outrem, quando este tiver contribuído para fundar essa confiança e ela se justifique igualmente em face de outras circunstâncias do caso concreto. Essa relevância jurídica pode levar a atribuir efeitos jurídicos a uma situação tão-só aparente, ou ficar-se, como sucederá normalmente, por criar obrigação de indemnização pela frustração das legítimas expectativas" (PINTO, 2005, p.125).
} 
hermenêutico do termo ajustado. Já uma segunda função exercida pela boa-fé materializa-se na integração. O princípio, nesse caso, é utilizado como meio de integrar as diversas disposições de um contrato, dando-lhes, ao final, um sentido coeso e consentâneo com os adequados valores éticos ${ }^{9}$.

A função interpretativa da boa-fé objetiva é mais assente e de fácil constatação. Interpretar com sopesamento na boa-fé implica na leitura dos termos ajustados tendo sempre como marco hermenêutico os padrões éticos estipulados pela cláusula geral. Costuma-se apontar que a interpretação pautada na boa-fé possui dois desdobramentos. O primeiro refere-se ao fato de que os negócios jurídicos devem ser interpretados de acordo com o seu sentido objetivo, aparente; não há que desvirtuar a vontade manifestada na avença contratual. Já o segundo desdobramento é encontrado nos momentos de dúvida interpretativa, traduzindo-se no dever de optar pelo significado que a boa-fé aponta como mais razoável. As chamadas cláusulas ambíguas devem ter seu sentido apurado em consonância com os deveres acessórios impostos pela cláusula geral (NORONHA, 1994, p. 152).

Já a função integrativa é reconhecida na utilização da boa-fé como parâmetro ético a servir de base para que se complete qualquer vazio existente entre as disposições manifestas da vontade dos contratantes. Isso significa dizer que a boa-fé, por meio dos seus intrínsecos deveres laterais, atuará como fonte de obrigações de eventuais conteúdos que não tenham sido clausulados pelo instrumento contratual. A integração pode ser compreendida no preenchimento de lacunas por meio de necessários deveres de colaboração mútua que as partes devem ter. Para além do conteúdo atermado e do fixado em lei, existem outras fontes obrigacionais que decorrem exatamente da chamada função integrativa.

Outra função da boa-fé, também relativa aos contratos, é a chamada função limitativa ou função controle, que atua como forma de impedir a ocorrência do abuso de direito ${ }^{10}$. O credor ou devedor, no exercício dos seus

\footnotetext{
${ }^{9}$ Sobre a diferença entre interpretação e integração, em consonância com a boa fé, Massimo Bianca (2000, p.425) aduz: "L'interpretazione secondo buona fede implica il riferimento al ragionevole affidamento della parte ma pur sempre nell'indagine sul contenuto dell'accordo. L'integrazione del contratto secondo buona fede presuppone invece che sia già accertato il contenuto dell'accordo e che a tale contenuto si aggiunga una determinazione di fonte legale la quale può completare o anche superare l'autoregolamento contrattuale. Riportare questa integrazione ad una presunta o ipotetica volontà delle parti vorrebbe dire falsare la realtà del contratto".

${ }^{10}$ Nesse sentido, assevera Theodoro Júnior $(2008$, p.23): "Função limitativa como meio de controlar o exercício do direito em busca de impedir ou sancionar o abuso do direito. Sendo ato ilícito o abuso de direito, quando este se configurar, o princípio da boa-fé conduzirá à nulidade, total ou parcial, do contrato, sem prejuízo da reparação do dano sofrido pela vítima".
} 
direitos, não pode exceder os limites impostos pela boa-fé. Isso significa que a autonomia reconhecida à parte encontra perímetros que não devem ser transpostos, sob pena de configurarem um ato antijurídico (NORONHA, 1994, p. 167).

Importante realçar, ainda, que a boa-fé deve ser seguida em todos os momentos da contratação. Assim, o referido viés principiológico vincula as partes desde a fase pré-contratual (culpa in contrahendo), perfilhando toda a fase de negociações do conteúdo da avença ${ }^{11}$. Em momento imediatamente posterior, tem-se que a atenção à boa-fé deve ser mantida durante toda a execução e cumprimento do termo acordado. E, por último, é importante salientar que mesmo após a finalização do contrato, as partes estão submetidas ao cumprimento dos deveres oriundos da cláusula geral de boa-fé ${ }^{12}$.

Após esse sucinto panorama acerca da boa-fé objetiva, observa-se, pois, que o referido princípio passa a exercer uma função de otimização do contrato, não só de natureza cível, mas, também, comercial. Isso se dá de duas maneiras diversas. A primeira concretiza-se, exatamente, na imposição de deveres laterais, como a cooperação e a proteção de interesses mútuos. Essas injunções que emanam do princípio fazem com que se propicie a realização positiva do contrato, protegendo as partes e satisfazendo seus interesses obrigacionais. A segunda forma de otimização dá-se pela elevação da boa-fé à referida categoria de cânone de interpretação e integração do contrato consoante à função que este deve desempenhar (MARTINS-COSTA, 2002, p. 80).

\section{AS ORIGENS DO DIREITO COMERCIAL E A IMPORTÂNCIA DOS USOS E COSTUMES}

Para compreender a formação histórica da boa-fé objetiva no âmbito do direito comercial, demonstra-se necessária a compreensão da própria origem desse ramo do direito.

\footnotetext{
${ }^{11}$ Sobre a boa-fé na fase pré-contratual, assevera Bianca (2000, p.162):" Obblighi tipici di buona fede nella fase precontrattuale sono, sotto il profilo della lealtà, gli obblighi di a) informazione, b) chiarezza e c) segreto, e sotto il profilo della salvaguardia, d ) l'obbligo del compimento degli atti necessari per la validità ed efficacia del contratto".

${ }^{12} \mathrm{Na}$ mesma acepção: "Good faith and fair dealing are required in the formation, performance and enforcement of the parties' duties under a contract, and equally in the exercise of a party's under the contract. [...] The concept is, however, broader than any specific applications. Its purpose is to enforce community standards of decency, fairness and reasonableness in commercial transactions". (THE COMMISSION ON EUROPEAN CONTRACT LAW, 2000, p.113).
} 
Habitualmente, os teóricos do direito comercial costumam apontar a Idade Média como sendo o período de surgimento da aludida categoria normativa ${ }^{13}$. Apesar de não haver dúvidas quanto à existência de pretéritas redes de tráfego comercial, até então, não se demonstrava necessário um regramento próprio que fosse aplicado apenas às transações de ordem mercantil. Algumas condições precisavam materializar-se para que o direito comercial surgisse e se desenvolve de forma autônoma. Sobre o aludido contexto, discorre Francesco Galgano (1990, p. 28):

As condições verificar-se-iam muito mais tarde, entre os séculos XI e XII, e gerar-se-iam a partir da crise do sistema feudal, no plano político, e da economia senhorial, no plano econômico. Estas condições determinam-se à medida que o declínio da economia senhorial permite um ressurgimento do tráfego e toma corpo uma nova classe de mercadores, a quem a crise interna do sistema feudal permite uma actuação, jamais conhecida até então, não apenas no campo da iniciativa econômica mas também no campo político. O novo grupo social pôde constituir organizações de classe próprias, como o são as corporações, e o sistema municipal permite-lhe fundar as suas próprias estruturas políticas, mediante as quais pode afirmar a sua condição de classe e exercer uma função dirigente sobre as demais classes.

Vê-se, por consequência, que o direito comercial surgiu como produto da atuação de uma classe, em decorrência da necessidade de veiculação de normas particulares para a solução de seus problemas contingenciais. Com o reflorescimento do tráfego mercantil, os comerciantes, agrupados em suas respectivas corporações de ofício, cuidaram de elaborar normas que propiciassem segurança e agilidade às suas transações negociais. $\mathrm{O}$ excessivo formalismo característico do direito civil vigente àquela época - e a oposição existente contra a usura - marca distintiva do direito canônico - impediam que as tratativas fossem celebradas de maneira célere e minimamente seguras para os mercadores. Fez-se necessária a criação de uma regulação própria: o ius mercatorum.

Importante perceber que as normas surgidas nesse contexto possuíam natureza essencialmente consuetudinária. As situações negociais vivenciadas

\footnotetext{
${ }^{13}$ Nesse ponto, Marcelo Andrade Féres (2004, p. 38) afirma: "Os estudiosos do Direito Comercial não são unânimes quanto ao seu surgimento. Há quem perceba a existência de ditames de índole mercantil em diplomas legislativos antigos, como, por exemplo, no Código de Manu, na Índia, ou no Código do Rei Hammurabi”.
} 
de maneira contínua pelos comerciantes materializavam o ponto inicial para elaboração de um instrumento de salvaguarda por parte das corporações de ofício. A prática do comércio era o elemento a informar as necessidades conjunturais existentes e, por consequência, a fornecer os instrumentos normativos perquiridos pelos mercadores.

Em verdade, é possível constatar que as corporações buscaram transformar costumes e usos comerciais em normas de regência entre os comerciantes, denotando o importante aspecto subjetivo que circundava a matéria: o ius mercatorum aplicava-se apenas aos mercadores inscritos em suas respectivas corporações de ofício.

Os usos e costumes ${ }^{14}$ alcançam, assim, uma importância ímpar no direito comercial. Por se tratar de um ramo em que a prática, habitualmente, precede a regulação, é possível constatar que o exercício contínuo de determinados atos leva à sua materialização em normas. Nesse sentido, Rubens Requião (2010, p 53) aduz que

[...] por ter sido inicialmente um direito consuetudinário, fundado nos estilos dos comerciantes medievais, o direito comercial mantém tradicionalmente o prestígio dos usos e costumes como regra subsidiária de suas normas. As codificações, surgidas no século XIX, sintetizaram os usos e costumes já incorporados nos repositórios organizados pelas corporações. O legislador das codificações não podia, portanto, desconhecer ou desprezar a inteligência inventiva e a engenhosa capacidade de técnica dos comerciantes de criarem normas práticas, para assegurar o desenvolvimento de seus negócios, com instrumentos novos e descerrando novos horizontes.

Assim, as práticas e os comportamentos implementados pelos comerciantes revelam-se como meios adequados para materializar a segurança das transações negociais. O mercado passa a estar adstrito à confiança existente na repetição e constância de determinadas condutas tomadas pelos mercadores ${ }^{15}$. Com o crescente desenvolvimento do tráfego, os usos e costumes

\footnotetext{
${ }^{14}$ Importante salientar que alguns doutrinadores distinguem usos de costumes, "vendo nos costumes uma regra mais imperativa do que os usos, os quais seriam simplesmente convencionais" (REQUIÃO, 2010, p. 53).

${ }^{15}$ Nesse ponto, Rubens Requião (2010, p. 54) apresenta interessante adução relacionada aos usos interpretativos: "Os usos interpretativos ou convencionais são os que decorrem da prática espontânea dos comerciantes em suas relações comerciais. Integram-se nos contratos como cláusulas implícitas ou tácitas, e de tal forma ingressam nos negócios que seu uso constante os torna implícitos, sendo desnecessário enunciá-los expressamente. Recebem eficácia da simples vontade das partes".
} 
vinculantes não mais se demonstraram restritos somente às práticas dos mercadores, mas passaram, por outro lado, a também alcançar as práticas mercantis que extrapolavam os limites da corporação de ofício. Constata-se, por conseguinte, uma verdadeira função uniformizadora dos usos e costumes mercantis, gerando expectativas de respeito e cumprimento dos mesmos, em razão da regularidade encontrada ${ }^{16}$.

O direito comercial revela, assim, a sua natureza cosmopolita. A tendência de superação das unidades políticas, na busca da uniformização das práticas negociais em âmbito internacional, materializa-se como uma constante no âmbito da juridicidade mercantil. Além disso, por se desenvolver, principalmente, a partir da práxis, esse ramo apresenta-se sempre à frente dos desenvolvimentos teóricos ou mesmo da promulgação de instrumentos legislativos. A criatividade do comerciante é, assim, o vetor evolutivo da ciência jurídica comercial e, por essa razão, a eficiência dos instrumentos utilizados é verificada em maior amplitude.

\section{A ORIGEM DA BOA-FÉ OBJETIVA: OS JURAMENTOS DE HONRA}

Como assinalado por Menezes Cordeiro, a fides romana constitui a base linguística e conceitual da boa-fé (CORDEIRO, 2007, p. 53). Originalmente, a referida locução era dotada de conteúdo sacro e estava adstrita ao culto da deusa Fides, entidade responsável pela personificação e proteção da palavra dada. Contudo, constata-se, em Roma, uma utilização fragmentada da expressão, estando também ligada às situações jurídicas existentes entre cliens e patronus, ou caracterizando as relações exteriores com outros povos.

A expressão boa-fé, no entanto, surge no contexto do processo formulário romano. Os bonae fidei iudicia consubstanciavam ações nas quais era dada ao pretor uma maior margem de atuação jurisdicional, de modo a enfrentar novas questões que se pusessem. Nesse contexto, têm-

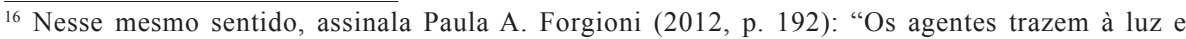
adaptam modelos de comportamento que, aos poucos, vão se espraiando porque se mostram eficientes e adequados à satisfação de determinadas necessidades. Gera-se, assim, regularidade do agir e possibilidade de previsão do comportamento que será adotado pelo parceiro comercial. Esses esquemas - que normalmente atuam em prol do tráfico - espraiam-se ao serem imitados por outros agentes. Daí a força uniformizadora dos usos e costumes, que tendem a planificar o comportamento das empresas".
} 
se os denominados contratos de boa-fé, em que se permitia a amenização do formalismo, em prol de uma apreciação jurisdicional afeta a outros elementos materiais encontrados nos litígios ${ }^{17}$.

Com o fim do processo formulário, constata-se uma diluição no uso da expressão boa-fé, sem uma utilização pautada em critérios técnicos. Nesse ínterim, verifica-se o surgimento do viés subjetivo do que hoje se concebe por boa-fé, estando correlacionado à posse e ao instituto da usucapião, ao se idealizar um novo requisito, de ordem qualitativa, a ser perfilhado para a aquisição da propriedade. Assim, o possuidor só adquiria o domínio de certa coisa quando ignorava a existência de vícios e empecilhos para tanto (CORDEIRO, 2007, p. 113).

Não obstante encontrar-se em Roma a origem da boa-fé subjetiva, o mesmo não se pode dizer com relação à boa-fé em sua acepção objetiva. Não se constata no direito romano qualquer compreensão da boa-fé como padrão de conduta a conduzir o comportamento dos indivíduos, e ainda menos crível demonstra-se a tentativa de busca das raízes dos deveres laterais naquele ordenamento.

O surgimento da boa-fé objetiva parece remontar a um contexto diverso, adstrito à cultura jurídica germânica medieval e a seus juramentos de honra.

Como assinalado por R. C. van Caenegem (1999, p. 26), antes das invasões bárbaras, os germânicos eram governados pelo direito primitivo de suas tribos, que se baseava em costumes imemoriais transmitidos por uma tradição puramente oral. Os juramentos de honra faziam parte dessa conjuntura pautada na tradição.

Treu und Glauben é o termo em alemão para designar a boa-fé. Nesse ponto, é importante assinalar a existência de uma diferenciação de natureza semântica. Treu pode ser traduzido por lealdade, enquanto Glauben reporta-se à crença. Segundo Menezes Cordeiro, a similitude estreita entre Treu e Glauben, semanticamente considerados, possibilitou o emprego

\footnotetext{
${ }^{17}$ Nesse contexto, António dos Santos Justo (2003, p. 27) caracteriza os contratos de boa-fé: "São de boa fé os contratos protegidos por actiones bonae fidei. Os contratos de direito estrito são tutelados por actiones stricti iuris. Naquelas, o juiz deve apreciar todas as circunstâncias que tenham ocorrido ( v.g., o dolo, o medo, etc.) e considerar tudo o que é exigível entre pessoas justas e leais. Nestas, deve observar rigorosamente o que foi acordado sem atender a qualquer circunstância que tenha influenciado o conteúdo da obligatio".
}

SCIENTIA IURIS, Londrina, v.17, n.2, p.9-28, dez.2013 
conjunto das duas expressões e, depois, a sua fusão em uma fórmula par (CORDEIRO, 2007, p. 169). Assim como a bona fides, no decurso histórico, a utilização da aludida expressão padeceu de imenso alargamento, documentando-se seu emprego como confiança, boa-fé em sentido subjetivo ou credibilidade. Denota-se, por conseguinte, que o emprego de Treu und Glauben não estava pautado em critérios uniformes de técnica jurídica, concretizando, em verdade, uma utilização generalizada e diversificada.

A boa-fé germânica perde a sua absoluta abstração quando analisada no contexto da figura do juramento de honra. Por meio da utilização desse instrumental, fazia-se possível materializar o reforço da relação de respondência pessoal, dobrando um débito (CORDEIRO, 2007, p. 172). Apesar da ausência de unanimidade doutrinária quanto aos efeitos oriundos do não cumprimento de um juramento, é possível constatar que, nesse contexto

[...] a boa fé assumiria o conteúdo do juramento de honra, traduzido no dever de garantir a manutenção e o cumprimento da palavra dada. Nesta linha evolutiva, a boa fé germânica traduziria, ainda, a confiança ou crédito cristalizados em certa pessoa, evoluindo, depois, para a segurança geral, inspirada nessa confiança, estabelecida a nível de comunidade jurídica e, por osmose, para a regra de comportamento social, necessário ao estabelecimento dessa confiança. No comércio, em especial, revestiria o conteúdo do cumprimento exacto dos deveres assumidos (CORDEIRO, 2007, p. 173).

Percebe-se, assim, que o gérmen para o desenvolvimento da boa-fé objetiva está delineado na cultura jurídica germânica medieval. No panorama dos juramentos de honra, já é possível cogitar de um padrão social, inspirado na confiança e, nesse contexto, pode-se conjeturar que os comerciantes exigiam vinculações mais fortes, em decorrência do necessário cumprimento do objeto pactuado em suas avenças. Tal afirmação ganha ainda mais relevância, se observado o contexto de direito consuetudinário em que se desenvolviam essas relações jurídicas. 


\section{DESENVOLVIMENTO DA BOA-FÉ OBJETIVA PELA JURISPRUDÊNCIA COMERCIALALEMÃ}

Com a entrada em vigor do Código Civil Alemão de 1900 (BGB), observou-se uma difusão no emprego da boa-fé objetiva, em decorrência da positivação naquela codificação. Figuras adstritas à boa-fé objetiva, como a exceptio doli, a suppressio, a alteração de circunstâncias ou a interpretação contratual complementadora, surgem e se desenvolvem nesse período (CORDEIRO, 2007, p. 314).

No entanto, acerca da referida difusão no emprego da boa-fé objetiva, Menezes Cordeiro (2007, p. 315) apresenta a seguinte objeção:

A difusão da boa fé objectiva, na sequência da entrada em vigor do BGB, é apenas aparente. Para além de todo um complexo de contributos culturais e científicos que confluíram nesse sucesso, assistiu-se apenas a uma continuidade de práticas judiciais assentes numa experiência extensa: a da jurisprudência comercial alemã.

Como visto, o direito comercial se apresenta originalmente como norma eminentemente consuetudinária, tratando-se do ramo jurídico ligado, de maneira mais candente, aos usos e costumes do tráfego. A dinâmica característica do comércio dá uma grande ênfase à prática, permitindo o ganho de celeridade e de flexibilidade para o enfrentamento de situações permanentes e contingenciais ${ }^{18}$. Essa propriedade do direito comercial, aliada à sua busca pela diminuição do elemento formal, revela o vetor para o desenvolvimento prático da boa-fé objetiva. A autônoma jurisdição comercial pode, assim, construir decisões que materializavam aplicações do que, hoje, se concebe como cláusula geral de padrão conduta.

Conforme exposto por Menezes Cordeiro (2007, p. 316), as necessidades comerciais levaram as quatro cidades livres do Ocidente alemão - Lübeck, Hamburgo, Bremen e Frankfurt - a estabelecer, no ano

\footnotetext{
${ }^{18}$ Acerca do elemento prático, discorre Alfredo Rocco (1931, p. 151): "Dos dois elementos que concorrem no processo de interpretação das leis, para determinar o conteúdo e o alcance exacto da vontade geral declarada na norma - o elemento histórico e o elemento prático - sabido é que este último é incomparavelmente o mais importante na interpretação do direito comercial. [...] Essa particular importância resulta da própria natureza do direito comercial, que regula relações numa constante formação e contínua transformação, e para as quais a norma jurídica aqui existente não foi escrita, tendo apenas de lhes ser adaptada".
}

SCIENTIA IURIS, Londrina, v.17, n.2, p.9-28, dez.2013 
de 1815, um tribunal superior de apelação comercial, com jurisdição sobre as cidades em causa, denominado Oberappellationsgericht zu Lübeck. As decisões do aludido tribunal apresentam-se, em seu conjunto, como tópicas. Ao lado da acepção boa-fé em seu sentido subjetivo, constata-se o seu uso para exprimir um modo de exercício das posições jurídicas, uma fórmula de interpretação dos contratos ou, até, uma fonte de deveres, independentemente do fenômeno contratual (CORDEIRO, 2007, p. 317).

A título de exemplo, por meio de uma decisão do aludido tribunal do comércio, datada de 14 de maio de 1850, reconheceu-se o dever de diligência que as partes devem ter uma com a outra. Tratava-se de ação movida para o pagamento de mercadorias encomendadas e entregues. O réu respondeu, alegando vícios e postulando a devolução. O Tribunal entendeu que o destinatário de mercadorias, quando não queira aceitá-las, deve comunicálo ao devedor o mais breve possível. A aludida decisão não tinha apoio em regra, sendo extraída apenas com apoio na bona fides. Em outro caso, apresentado em 17 de julho de 1822, o tribunal condenou um comerciante em uma quantia indenizatória por não conclusão de um contrato válido, materializando verdade hipótese de responsabilidade pré-contratual (culpa in contrahendo) (CORDEIRO, 2007, p. 318-319). Assim, a prática e a jurisprudência mercantil revelam-se como as responsáveis pelos primeiros contornos do que hoje se compreende por boa-fé objetiva. Nesse contexto, assevera Menezes Cordeiro (2007, p. 319):

A boa fé objectiva ganha um relevo próprio, com projecção a nível decisório. Ainda que num estádio embrionário, denota-se já a presença dos vectores futuros de evolução do conceito; o exercício inadmissível de posições jurídicas a interpretação objectiva e os deveres de comportamento no tráfego. A própria boa fé subjectiva é conectada, se bem se atentar, com factores objectivados: a situação de confiança criada.

A utilização da boa-fé em sua acepção objetiva, por parte da jurisprudência comercial alemã, não se apresentou em consonância com nenhum desenvolvimento de ordem doutrinária. Trata-se, na verdade, da persecução de valores ligados ao comportamento das partes, tendo por alicerce único a prática vivenciada no tráfego mercantil. $\mathrm{O}$ acolhimento do instituto pela doutrina e seu conseguinte desenvolvimento científico restaram 
postergados em razão do formalismo que se anunciava no direito vigente à época (MARTINS-COSTA, 2000, p. 211).

\section{O DIREITO COMERCIAL BRASILEIRO E O DESENVOL- VIMENTO DA BOA-FÉ OBJETIVA}

O desenvolvimento do instituto da boa-fé objetiva, no Brasil, seguiu caminhos próprios. $\mathrm{O}$ seu reconhecimento como cláusula geral a impor a tomada de um padrão de comportamento é usualmente identificado como uma conquista do denominado Direito do Consumidor. Não se verificou a efetivação de uma conquista a partir da práxis, mas sim, contrariamente, foi o direito legislado que se antepôs aos porvindouros desenvolvimentos doutrinários e jurisprudenciais acerca do tema.

É importante destacar, no entanto, que o Código Comercial brasileiro de 1850 foi o primeiro instrumento legislativo, no ordenamento jurídico pátrio, a conceber a boa-fé objetiva, tratando-a como necessário vetor interpretativo dos contratos de natureza comercial.

Art. 131 - Sendo necessário interpretar as cláusulas do contrato, a interpretação, além das regras sobreditas, será regulada sobre as seguintes bases:

1 - a inteligência simples e adequada, que for mais conforme à boa fé, e ao verdadeiro espírito e natureza do contrato, deverá sempre prevalecer à rigorosa e restrita significação das palavras;

2 - as cláusulas duvidosas serão entendidas pelas que o não forem, e que as partes tiverem admitido; e as antecedentes e subseqüentes, que estiverem em harmonia, explicarão as ambíguas;

3 - o fato dos contraentes posterior ao contrato, que tiver relação com o objeto principal, será a melhor explicação da vontade que as partes tiverem no ato da celebração do mesmo contrato;

4 - o uso e prática geralmente observada no comércio nos casos da mesma natureza, e especialmente o costume do lugar onde o contrato deva ter execução, prevalecerá a qualquer inteligência em contrário que se pretenda dar às palavras;

5 - nos casos duvidosos, que não possam resolver-se segundo as bases estabelecidas, decidir-se-á em favor do devedor.

No entanto, a jurisprudência não aplicou a boa-fé objetiva, desempenhando a sua intrínseca função de cláusula geral (MARTINS- 
COSTA, 2004, p. 88). Em verdade, trata-se de texto que não foi implementado no plano prático, restando letra morta em um instrumento normativo.

Importante ressaltar, contudo, que os tribunais brasileiros, àquela época, sequer detinham dados teóricos necessários para o reconhecimento e aplicação da boa-fé objetiva como cânone interpretativo a exigir dos contratantes padrões de comportamento. É preciso lembrar, ainda, que a concepção de contrato vigente estava adstrita ao modelo liberal, marcado pelo acordo livremente manifestado pelas partes, no qual não era lícito ao juiz interferir no que fora pactuado $^{19}$.

Não obstante, a ausência de validação pelos tribunais, é interessante notar que o comercialista Carvalho de Mendonça, apoiando-se em Goldschmidt, já demonstrava a preocupação com o elemento ético a perfilhar as negociações de natureza mercantil. Nesse sentido, o autor assevera:

Entre estes conhecimentos nota-se a chamada doutrina da prudencia commercial, o modo de proceder no trafico mercantil, conjuncto de principios que ensinam a dar effeito a escopos licitos sómente mediante meios licitos. Mostra-nos Goldschmidt a grande dose que exerceram na formação do direito commercial os momentos ethicos (Treu und Glauben, bona fides). O genio ethico-juridico dos povos da antiguidade classica, especialmente dos romanos, escreve o sabio autor, criou o typo valioso por todo o tempo, do homem de negocios honesto (bonus vir), tão distante do egoismo brutal, como da ultraterrena renuncia a qualquer objectivo pessoal. Esse poderoso factor manifesta-se no nosso direito commercial. O Codigo, nos arts. 142 e 181, acceita-o, assignalando as figuras do commerciante acautelado, do commerciante activo e probo, e, no art. 131, n. 1, dá especial realce à bôa fé nos negócios jurídicos mercantis (CARVALHO DE MENDONÇA, 1933, p. 33).

\footnotetext{
${ }^{19}$ De acordo com Luciano Beneti Timm (2008, p. 39), "a concepção elementar do modelo (liberal) é a de que o legislador deixa uma esfera normativa dos comportamentos sociais para os próprios indivíduos negociarem, barganharem, cada qual sendo responsável pelo que é melhor para si. Cada um saberá cuidar melhor do seu interesse, gerando com isso a justiça. Os conflitos serão evitados na medida que se reconheça esta esfera normativa privada ampla e que o Estado garanta o cumprimento desses pactos livremente formados".
} 
A ausência de reconhecimento da boa-fé objetiva como princípio interpretativo por parte da jurisprudência não retira a importância do direito comercial legislado na consagração do instituto no ordenamento jurídico brasileiro. A tentativa de sobrepor o direito positivo às práticas verificadas no tráfego negocial não se apresenta como caminho habitual a ser tomado pelo direito mercantil. Talvez, em razão desse fato, a boa-fé objetiva não tenha se difundido no plano prático, pois deveria estar primeiramente arraigada nos usos e costumes do tráfego.

\section{CONCLUSÕES}

O direito comercial é dotado de características particulares que lhe dão uma feição cosmopolita no ordenamento jurídico. Via de regra, a criatividade dos comerciantes é a válvula a impulsionar o posterior desenvolvimento de consentâneos instrumentos legislativos. Constata-se, ainda, que a importância dos usos e costumes nesse ramo jurídico acentua o seu caráter inovador.

A boa-fé objetiva apresenta essencial importância no tráfego mercantil. A despeito do cerne empresarial estar adstrito à busca de lucros crescentes, hoje, não se pode pensar em um direito comercial que não perpasse pelas ponderações de cunho ético, características da boa-fé objetiva.

Apesar da existente tradição do estudo da boa-fé objetiva como instituto ligado ao direito civil, as fontes históricas parecem demonstrar que a sua origem reside nos juramentos de honra e no desenvolvimento impelido pela jurisprudência comercial alemã. $O$ caráter consuetudinário desse direito e a necessidade de resguardo da confiança nas transações negociais travadas pelos comerciantes parecem ser os elementos propulsores ao desenvolvimento da boa-fé como padrão ético de comportamento dos agentes.

No Brasil, o processo histórico de desenvolvimento da boa-fé objetiva também está diretamente ligado ao direito comercial. O Código Comercial de 1850 foi o primeiro instrumento legislativo a contemplar a boa-fé objetiva adstrita à interpretação dos contratos de natureza mercantil. Apesar de não ter alcançado aplicação no plano prático, não sendo observada na 
jurisprudência que se seguiu a codificação, é importante a constatação do ineditismo no tratamento dado ao tema pelo direito comercial positivo.

Não obstante, hoje, a boa-fé objetiva é princípio de suma importância para o direito privado como um todo e, notadamente, para o direito comercial, campo em que a confiança se faz demasiadamente necessária. Resta, assim, a certeza de que a vanguarda característica do direito comercial é responsável por uma essencial influência na concretização e no desenvolvimento do princípio da boa-fé objetiva.

\section{REFERENCIAS}

AZEVEDO, Antônio Junqueira de. A boa-fé na formação dos contratos. Revista da Faculdade de Direito da USP, São Paulo, v.87, n.3, p.7887, set.-dez. 1992.

BIANCA, C. Massimo. Diritto civile: il contratto. 2.ed. Milano: Giuffrè, 2000.

CAENEGEM, R. C. van. Uma introdução histórica ao direito privado. 2. ed. Tradução de Carlos Eduardo Lima Machado. São Paulo: Martins Fontes, 1999.

CARVALHO DE MENDONÇA, José Xavier. Tratado de direito commercial brasileiro. 2. ed. Rio de Janeiro: Freitas Bastos, 1933. v.1.

CORDEIRO, António Manuel da Rocha e Menezes. Da boa fé no direito civil. Coimbra: Almedina, 2007.

FÉRES, Marcelo Andrade. Empresa e empresário: do código civil italiano ao novo código civil brasileiro. RODRIGUES, Frederico Viana (Org.). Direito de Empresa no Novo Código Civil. Rio de Janeiro: Forense, 2004.

FORGIONI, Paula A.. A evolução do direito comercial brasileiro: da mercancia ao mercado. 2.ed. São Paulo: Revista dos Tribunais, 2012. 
GALGANO, Francesco. História do direito comercial. Tradução de João Espírito Santo. Lisboa: Editores, 1990.

JUSTO, António dos Santos. Direito Privado Romano - Direito das Obrigações - II. Coimbra: Coimbra Editora, 2003. (Studia iuridica, n.76).

MARTINS-COSTA, Judith. A boa-fé como modelo. Roma e America. Diritto Romano Comune. Rivista di diritto dell'integrazione e unificazione del diritto in Europa e in America Latina, Roma, n. 13, 2002.

MARTINS-COSTA, Judith. A boa-fé no direito privado: sistema e tópica no processo obrigacional. São Paulo: Revista dos Tribunais, 2000.

MARTINS-COSTA, Judith. Os campos normativos da boa-fé objetiva: as três perspectivas do direito privado brasileiro. Estudos de Direito do Consumidor, Coimbra, n. 6, 2004.

NORONHA, Fernando. O direito dos contratos e seus princípios fundamentais. São Paulo: Saraiva, 1994.

PINTO, Carlos Alberto da Mota. Teoria geral do direito civil. 4. ed. Rev. e atual. por António Pinto Monteiro e Paulo Mota Pinto. Coimbra: Coimbra Editora, 2005.

REQUIÃO, Rubens. Curso de direito comercial. Rev. e atual. por Rubens Edmundo Requião. 29. ed. São Paulo: Saraiva, 2010. v.1.

ROCCO, Alfredo. Princípios de direito comercial. Tradução de Cabral de Moncada. São Paulo: Saraiva, 1931.

THE COMMISSION ON EUROPEAN CONTRACT LAW. Principles of European Contract Law. Netherlands: Kluwer Law International, 2000 . 
THEODORO JÚNIOR, Humberto. O contrato e sua função social. 3. ed. Rio de Janeiro: Forense, 2008.

TIMM, Luciano Benetti. O novo direito contratual brasileiro. Rio de Janeiro: Forense, 2008.

Artigo recebido em 04/09/13 e Aprovado para publicação em 01/10/13

Como citar: PEREIRA, Fábio Queiroz. O direito comercial e a formação histórica do princípio da boa-fé objetiva. Scientia Iuris, Londrina, v.17, n.2, p.9-28, dez.2013. DOI: 10.5433/2178-8189.2013v17n2p9. 